IRA-International Journal of Education \&

Multidisciplinary Studies

ISSN 2455-2526; Vol.15, Issue 03 (June 2019)

Pg. no. 104-109.

Institute of Research Advances

http://research-advances.org/index.php/IJEMS

\title{
Chinese Culture Translation and Communication: A Case Study of A Dream of Red Mansions
}

Zhang Xueyu

School of Foreign Studies, Yangtze University, Hubei, 434023 PRC China.

Type of Work: Peer Reviewed

DOl: http://dx.doi.org/10.21013/jems.v15.n3.p3

\section{How to cite this paper:}

Xueyu, Z, (2019). Chinese Culture Translation and Communication: A Case Study of A Dream of Red Mansions. IRA International Journal of Education and Multidisciplinary Studies (ISSN 2455-2526), 15(3), 104-109.doi: http://dx.doi.org/10.21013/jems.v15.n3.p3

(C) Institute of Research Advances.

This work is licensed under a Creative Commons Attribution-Non Commercial 4.0 International License subject to a proper citation to the publication source of the work.

Disclaimer: The scholarly papers as reviewed and published by the Institute of Research Advances (IRA) are the views and opinions of their respective authors and are not the views or opinions of the IRA. The IRA disclaims of any harm or loss caused due to the published content to any party.

Institute of Research Advances is an institutional publisher member of Publishers International Linking Association Inc. (PILA-CrossRef), USA. The institute is an institutional signatory to the Budapest Open Access Initiative, Hungary advocating the open access of scientific and scholarly knowledge. The Institute is a registered content provider under Open Access Initiative Protocol for Metadata Harvesting (OAI-PMH).

The journal is indexed \& included in WorldCat Discovery Service (USA), CrossRef Metadata Search (USA), WorldCat (USA), OCLC (USA), Open J-Gate (India), EZB (Germany) Scilit (Switzerland), Airiti (China), Bielefeld Academic Search Engine (BASE) of Bielefeld University, Germany, PKP Index of Simon Fraser University, Canada. 


\begin{abstract}
By comparing and analyzing the differences between Yang Xianyi's and Hawkes' versions of A Dream of Red Mansions from the perspective of communication studies to uncover the deficiencies neglected by most Chinese scholars on Chinese culture translation. To improve the communication effect, China must make an account of the potential of Western sinologists and the process of translation and dissemination.
\end{abstract}

Keywords: Chinese culture; A Dream of Red Mansions; translation; communication

\title{
1 Introduction
}

Since the Chinese strategy as "Chinese culture going out" was put forward, thousands of literary, films and television works have been translated with a seeming good translation quality into the western market. However, only a tiny minority has succeeded to come to the view of western readers. Quite a few Chinese translators consider the factors affecting acceptance. Therefore, the focus needs to convert to the process of "going out", not the translation itself.

Communication science is gradually taken seriously and applied to translation studies over the years in China. And more and more Chinese scholars have reached an agreement that the law of the occurrence and the development of communication behaviors and communication process should be incorporated in translation studies.

\section{The Relationship Between Translation and Communication}

XieTianzhen (2018) has claimed in his work Introduction to Medio-Translatology (2nd Edition)that it is not a simple language conversion but culture conversion if push Chinese culture into the world by translation. Text translation is just a basic job and the beginning of dissemination. Before translation, there is a question of what to translate, and after that, there are still some problems left like communication, affection, acceptation, and dissemination.

\subsection{The Essence of Translation is Communication}

Simply speaking, communication science studies how human beings communicate to exchange information by using symbols. The translation is considered as a bridge of different languages which plays a very important role in thinking, knowledge and culture communication. Thus, the framework of communication studies is very similar to that of translation studies. Translation also includes the factors of translator, audience, translation channel, translation content and translation effect.

The history is also not too long that the western scholars applied communication theories into translation studies. Wilss W, a German translator, has constructed the theory of communication in translatology. On the basis of studying the subject of information transmission, Wilss (1982) holds that translation is a special way of interlingual information transmission related to linguistic behavior and choice.

In China, Lv Jun (1997), who is an early one applying communication theories to discuss translation process, generalized that translation is a cross-cultural information exchange activity and the essence of translation is communication, which means that translation is a structured and dynamic process of information transmission. 


\subsection{The Two Problems in Culture Communication}

When Chinese culture walks into a new cultural context, the image and status are bound to change. From the perspective of communication, it is also easy to find out the problems in the process of translation.

One is that "Chinese culture going out" is never a simple problem of translation. XieTianzhen (2013) pointed out that it is a serious misunderstanding that once the translation is finished, the communication work also done at the same time, especially for those Chinese literary works. Communication should examine whether the translated text conforms to the language norms of the target language and whether the translated content conforms to the mainstream ideology and poetics of the target audience...Communication is often the key to a successful translation. (Bao Zhenying, 2014) "The most typical example is that Yang Xianyi's translation version of A Dream of Red Mansions, which was regarded as a classic by Chinese scholars in the early time, has not aroused much response in Western countries."(Zhen Youqi, Huang Yuying, 2016) One of the main reasons is that the translator may pay too much attention to the faithful expression of the novel in many aspects, including culture, but fail to take into account the relevant factors such as the way of cross-language communication, the way of communication and the reader's acceptance mentality. If so, it won't bring considerable benefits to "Chinese culture going out".

Another problem is the political sensitivity. It is undeniable that taking "culture going out" as a strategy is of great significance for indirectly improving China's cultural soft power. But like some scholar pointed out that too much emphasis on "culture going out" often leads some groups abroad to associate the strategy with cultural hegemony, which on the contrary, leads to their disgust and results in no gains or losses. (Wang Ning, 2011) Therefore, "culture going out" needs to be promoted step by step.

\section{Translation Model from the Perspective of Communication}

Harolld D.Lasswell (1948) published an article The Structure and Function of Communication in Society, proposing the $5 \mathrm{~W}$ linear propagation model, which is still popular among many Chinese scholars. The 5W model simply means who say what, in which channel, to whom, with what effect, which also defined the basic contents of communication research, namely, the study of communication subject, communication content, communication media, communication audience, and communication effect.

Although this model reveals the basic elements of communication, unlike the principles of communication within its own framework, translation is conducted across cultures, involving two different linguistic and cultural systems. In the translation process, the translator's handling of text is not free, and it is bound to be affected by the translator's internal and external environment. Therefore, it is impossible to achieve the static normative study as the traditional theory says, but more dynamic descriptive study should be carried out.

Prigogine, Belgian renowned physical biologist. Chen Yan (2002) summarizedPrigogine's dissipative structure as "far away from equilibrium open system, forming a dynamic and stable ordered structure through dissipative motion". From this perspective, the translation process can be regarded as an open system consisting of source language authors, source language texts, translators, target texts and target readers for information transmission, and a dynamic information transmission system, which 
reveals the two-way interactive nature of human communication. In the translation process, the translator should not only form an effective channel for information dissemination but also interact and communicate with the external environment system far from equilibrium so as to better preserve the value of the text itself. For example, if the two-way interaction cannot be completed smoothly, the translation participants will not become a part of the target culture, thus the customs, views and world outlook of that culture cannot be properly expressed in language.

Unfortunately, the translation process is not affected by only one system. Certainly, there are many other systems as noise-making such interaction and communication mutually exclusive and not be effectively transformed from one another.

German physicist Haken (1977) put forward the synergy theory. The synergistic effect refers to the overall or collective effect produced by the interaction of a large number of subsystems in an open system, which emphasizes the study of how to make the whole system stable through the coordination of subsystems. The translation is a process of information exchange between the two cultural-linguistic systems. When the source language system is transformed into the target language system, it must be pressured by external conditions such as patrons, ideology, and poetry to promote the smoothness of information in a certain communication. As a result, the two systems cause noise problems of the information dissemination. The main purpose of synergy is to reduce noise. In translation, the translator, as the main body of translation activities, consciously seeks and establishes a balance among the source text, source culture, translator, target text, target culture, and target readers. It is unavoidable that many external factors such as the translator's motivation, the status difference in the target culture or the source culture. On the basis of this, a synergistic effect is formed, so that the information can be transmitted to the target readers as accurately as possible. Just like some scholars concluded that communication is a source system, which can influence the target system by manipulating optional symbols. (MaWeihua, 2010)

\section{A Case Study of A Dream of Red Mansions}

As mentioned above, compared with Yang's earlier versions, Hawkes' version is very successful in commercializing in the West. The communication subject: Hawkes is a famous contemporary British Sinologist and translator. he had a great affection for A Dream of Red Mansions. In 1970, he got a chance to cooperate with Penguin Publishing House and began the translation. In order to accomplish this masterpiece, Hawkes resigned as a professor, which showed that he was fascinated by sinology, especially redology. Penguin Publishing is one of the largest publishers of popular books in the world. It mainly publishes fiction and non-fiction works, as well as children's books, so the communication subject can be regarded as western business-sponsored scholars. Yang Xianyi was transferred to Beijing Foreign Language Publishing House as a translation expert in 1953 and began to translate A Dream of Red Mansions. Foreign Language Publishing House is a unified publishing agency of foreign publications, which is supported by the Chinese government; in other words, the communication subject is officially supported, Chinese scholar. Although Hawkes' was not supported by local authorities in the West, there was still a great noise about the difference of cultural status between native English and China. Faced to more age groups and types of audience, Penguin Publishing House has attracted much more readers who are somewhat interested in Chinese culture, not to mention the fact that Beijing Foreign Language Publishing House was not known to the Western public. Therefore, Hawkes' version 
achieved the two-way interactive nature for a wider range of sales channels and more English readers' feedbacks.

Furthermore, the motivation for translation of the two versions also affects the audience of communication. Because of the commercial nature of Hawkes'translation and his domesticated translation strategy, translation and communication were geared to English-speaking countries, especially for non-professional readers. Yang Xianyi believes that the best translation should not only focus on the original text but also the fewer annotations so that readers can enjoy and recall in the pleasure of reading. He emphasizes "faithfulness, expressiveness, and elegance" and mainly adopts alienation strategy. Therefore, even though the presupposition of the audience takes into account ordinary readers, most of the actual acceptance was only professional readers. This has a direct impact on the communication effect. Yang mixed his own translation ideas ignoring his work would be circulated in another linguistic system which has a different attitude and aesthetic criterion. Simply speaking, his "faithfulness, expressiveness and elegance" are not applicable in the West, and failed to reduce the noise and achieve synergistic effect to convey his information.

As far as Chinese academia is concerned, Yang's translation has received more attention in various senses. However, in Western English-speaking countries, Hawkes' has almost dominated. Jiang Fan (2007)surveyed Amazon's book reviews and found that Hawkes' version received unanimous praise at that time, w7hile Yang's version received a relatively low evaluation. In short, Hawkes' translation is not only popular with the general public but also favored by some professional readers. However, something has changed over times. This time when searching for comments from the readers in US Amazon, it will be a surprise that the 5-star of Yang's version has risen to 60\% while Hawkes' $65 \%$ which of course is still higher, but it shows a message that English readers, as far as redology is concerned, have begun to appreciate the alienation translation with an exotic perspective, confirming that "Culture going out" indeed needs to be promoted step by step.

\section{Enlightenment on "Chinese Culture G6oing Out"}

If China tries to disseminate other books or other forms of text, the efforts to reduce the noise is the key. Naturalization is more effective than foreignization. After all, foreignization translation can only satisfy a small number of professional readers, and its dissemination scope and impact are relatively limited. Mass ordinary readers are indispensable if China wants to push its culture to the world. Therefore, domesticated translations style is needed. They should first meet the expectations of the general readers and some professional readers who do not know much about Chinese culture, provide "Chinese culture" that they are willing and able to accept, cultivate and increase their interest, and constantly expand their understanding of Chinese culture. It takes a process from strangeness to familiarity, and then to acceptance. Chinese culture differs greatly from western culture, Western readers need a long period of time to gradually understand the ideological connotation of Chinese culture.

\section{References}

[1]. Bao Xiaoying. A case study of Hanshan Poetry's successful translation in the United States [J]. Foreign Languages (Journal of Shanghai Foreign Studies University), 2014, 37 (01): 65-71.

[2]. Chen Yan. Methodology of Communication Studies [M]. Beijing: Science Press, 2002

[3]. Glansdorff P, Prigogine I. Thermodynamic theory of structure, stability and fluctuations [M]. New York: 
Wiley-Interscience, 1971.

[4]. Haken H. Synergetics[J]. Physics Bulletin, 1977, 28(9): 412.

[5]. Jiang Fan. Stone Records of Other Countries: A Century-long History of English Translation of A Dream of Red Mansions [D]. Fudan University, 2007.

[6]. Lasswell H D. The structure and function of communication in society [J]. The communication of ideas, 1948, 37: 215-228.

[7]. Lv Jun. Translatology, a special field of communication [J]. Foreign Languages (Journal of Shanghai Foreign Studies University), 1997 (02): 40-45.

[8]. Ma Weihua. Viewing the Essence of Translation Process from the Perspective of Communication [J]. Journal of Jiangsu Institute of Education (Social Science), 2010, 26 (07): 114-116.

[9]. Wang Ning. Chinese culture going out, we must first break through the translation dilemma [N]. China Culture Daily, 2011-11-16 (3)

[10]. Wilss W. The science of translation: problems and methods[M]. John Benjamins Pub Co, 1982.

[11]. XieTianzhen. Chinese Culture Going Out Is not A Simple Translation Problem [N]. Journal of Social Sciences, 2013-12-05 (6).

[12]. XieTianzhen. Introduction to Medio-Translatology (2nd Edition) [M]. Beijing: Peking University Press, 2018

[13]. Zheng Youqi, Huang Biying. Literary translation studies in the perspective of communication science [J]. Modern Communication (Journal of China Media University), 2016, 38 (10): 165-166. 